\title{
How does time pressure influence emotional wellbeing? Investigating the roles of domain satisfaction and neuroticism among small-business owners
}

\author{
Filip Fors Connolly · Ingemar Johansson Sevä · Tommy Gärling
}

\begin{abstract}
Emotional wellbeing is related to the balance of positive and negative emotions associated with activities at work and in free time. We conjecture that time pressure is a factor reducing positive emotions and amplifying negative emotions, such that it has a negative relationship to emotional wellbeing. We found this to be the case in two studies based on survey data derived from samples of small-business owners in Sweden. In Study 1, the relationship between time pressure and emotional wellbeing is negative for small-business owners as well as for employed wage earners, although at work the former group experience both higher time pressure and higher emotional wellbeing than the latter. No differences in free time between the groups are observed. Study 2 provides support for the hypothesis that, both at work and in free time, domain satisfaction partially mediates the negative relationship between time pressure and emotional wellbeing. Supporting two additional hypotheses, the results indicate that neuroticism has a direct negative relationship with emotional wellbeing, and also an indirect relationship with emotional wellbeing mediated by time pressure, and furthermore moderates the negative relationship between time pressure and emotional wellbeing.
\end{abstract}

Keywords: Time pressure, emotional wellbeing, domain satisfaction, neuroticism, small-business owners

\section{Introduction}

In contemporary Western societies, people are frequently over-committed such that they experience time pressure. Although positively correlated with literal time scarcity, time pressure is not experienced unless people are actually aware of time limits, resulting in the experience of having too much to do in too little time (e.g., Strazdins et al., 2011). Several experimental laboratory studies demonstrate that time pressure has harmful consequences for work performance (for a review, see Proctor and van Zandt, 2018). Negative effects of time pressure are also observed in free time. Leiter and Durup (1996) found that long work hours impair performance of household tasks and caring duties. In further support, a cross-national survey (Haller et al. 2013) showed that a majority of people feel "rushed" even in free time. In affluent consumer societies, people face many competing opportunities that are attractive and affordable. It appears difficult then to not over-commit oneself

Tommy Gärling

University of Gothenburg

Tommy.garling@psy.gu.se

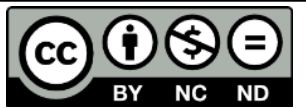


(Goodin et al., 2005). For instance, shopping is almost becoming a compulsion for many people (Manolis \& Roberts, 2012), to such an extent that it presumably infringes on time for other activities.

In previous studies, subjective wellbeing is often conceptualized as having two components: a cognitive judgment of satisfaction with life; and affective experiences of positive versus negative emotions (Busseri \& Sadava, 2011; Diener \& Suh, 1997; Tov, 2018). The latter component is frequently referred to as emotional wellbeing, whereby of interest is the balance of the frequency (or duration) and intensity of experiences of positive and negative emotions (Diener et al., 1985; Kahneman, 1999). Emotional wellbeing may be lowered by factors that reduce positive emotions and amplify negative emotions such as, for instance, worries for economic hardship (Mani et al., 2013), poor sleep quality (Kahneman \& Krueger, 2006), or long work commutes (Novaco \& Gonzales, 2009).

\subsection{Time Pressure and Emotional Wellbeing}

In this paper we investigate the relationship between time pressure and emotional wellbeing. Two previous studies have demonstrated a negative relationship between these two factors (Gärling et al., 2016; Ng et al., 2009). From a public health perspective, it is important to further investigate this negative relationship, since morbidity and mortality are found to increase with prolonged low emotional well-being (Diener \& Chan, 2011). From a policy perspective, in terms of looking for improvements at both the individual and societal levels, it is worth considering how time pressure may be alleviated by changing life circumstances (e.g. reducing work hours), as well as how coping with time pressure should be supported (e.g. providing restorative opportunities). To inform policy, it is therefore important to investigate (1) whether time pressure has a negative relationship to emotional wellbeing, (2) whether the relationship is related to life circumstances at work and in free time, and (3) whether there are differences between individuals and occupational groups.

A meta-analysis by Klug and Maier (2013) found that goal progress is positively related to emotional wellbeing. Conversely, impediments to goal progress may therefore have a negative relationship to emotional wellbeing. Gärling et al. (2014) proposed a conceptual model positing that time pressure is negatively related to emotional wellbeing by impeding progress of work, family, and free time goals associated with everyday routines. An empirical study by Gärling et al. (2016) supported this conceptual model, showing that the negative relationship between time pressure and emotional wellbeing is mediated by impediments to goal progress. Based on this 2016 study, here we investigate whether the relationship between time pressure and emotional wellbeing is mediated by domain satisfaction, and specifically satisfaction with work and free time. Since previous research has shown that domain satisfaction is related to goal progress (Lent et al. 2005), this mediation is theoretically plausible. A first hypothesis that we test in this paper is therefore whether a negative relationship between time pressure and emotional wellbeing is mediated by domain satisfaction.

Self-reported stress symptoms were found by Gärling et al. (2016) to be a parallel mediator of the negative relationship between time pressure and emotional wellbeing. This finding suggests that unsuccessful coping with time pressure may result in time stress, with characteristic changes in physiology, cognitions, feelings, and behavior (e.g., Hill Rice, 2012). We therefore raise the question of whether time pressure is stronger, or possibly more frequently experienced as time stress, by less emotionally stable people. Individuals scoring high on the Big-Five personality trait neuroticism are more likely to experience anxiety, worry, fear, anger, and depressed mood (Costa \& McCrae, 1985). They have furthermore been found to be more prone towards more negative perceptions of ambiguous and threatening stimuli (Lommen et al., 2010). In line with these findings, we conjecture 
that individuals high in neuroticism are likely to report higher time pressure than individuals low in neuroticism. No previous research has demonstrated this, but several studies have shown that neuroticism is negatively related to emotional wellbeing (e.g. Steel et al., 2008). Combining this finding with the possibility that time pressure is negatively related to emotional wellbeing, our second hypothesis is that time pressure mediates the relationship between neuroticism and emotional wellbeing.

Previous research has shown that neuroticism is related to emotional responsiveness to negative events (Suls, 2001). For instance, Hutchinson and Williams (2007) found that individuals who score high on neuroticism respond more strongly to daily hassles than individuals who score low on neuroticism, thus resulting in a stronger positive relationship between daily hassles and depression for these individuals. We argue that time pressure is an important component of daily hassles. Byrne et al. (2015) found that individuals high in neuroticism performed worse in a decisionmaking task than individuals low in neuroticism when confronted with both social pressure and time pressure. An explanation of why neuroticism moderates the relationship between stressful events and emotional distress may be that maladaptive coping strategies are adopted. For instance, highneuroticism individuals tend to use emotion-focused instead of problem-focused coping more frequently than low-neuroticism individuals do (Hutchinson \& Williams, 2007). Our third hypothesis is that neuroticism moderates the negative relationship between time pressure and emotional wellbeing.

\subsection{Vulnerability of Occupational Groups}

Individuals strongly engaged at work, perhaps in combination with demanding family obligations, are likely to have little free time for recreational activities that otherwise reduce time stress and increase emotional wellbeing (Trougakos et al., 2008). A lack of resources for recreation would reduce the capability to cope with time pressure, thus making people vulnerable to time stress. Stress is in turn negatively related to emotional wellbeing ( $\mathrm{Ng}$ et al., 2009). A key component of recreation activities is to psychologically maintain a distance from work and other demands that otherwise depletes mental resources and aggravates negative feelings (Sonnentag, 2012). Psychologically being away from work is commonly regarded as an affordance of the home, but work frequently performed at home diminishes the latter's recreation potential (Hartig et al., 2003).

Some occupational groups may be more vulnerable than other groups to time pressure and stress. According to previous research, one such potential group is small-business owners, whom we investigate in this study. Even though small-business owners display relatively high job autonomy, job satisfaction and life satisfaction, owning small businesses has been described as a "double-edged sword" (Prottas \& Thompson 2006). Compared to employed wage earners, small-business owners work longer hours (Parasuraman \& Simmers, 2001), experience more work-family conflict (Johansson Sevä \& Öun, 2015), and face higher demands at work (Nordenmark et al., 2012; Prottas \& Thompson, 2006). Small-business owners may therefore experience higher time pressure and lower emotional wellbeing than employed wage earners. It is also possible that, even in their free time, they may experience higher time pressure and lower emotional wellbeing if time pressure at work has a negative spill-over effect.

\subsection{Overview of Studies}


In Study 1 we use a survey of a representative sample of the adult Swedish population to examine whether small-business owners experience higher time pressure than employed wage earners at work and in free time, and whether the relationship between time pressure and emotional wellbeing is negative. In another larger sample of small-business owners, we test in Study 2 our three hypotheses of mediators and moderators of the relationship between time pressure and emotional wellbeing. Also in this study we measure time pressure and emotional wellbeing experienced at work and in free time.

\section{Study 1}

The aim of Study 1 is to investigate whether small-business owners at work and in free time experience higher time pressure than regular employed wage earners. We also provide an initial analysis of the relationship between time pressure and emotional wellbeing that we then examine more closely in Study 2.

\subsection{Sample and Procedure}

We used data from one of the Society, Opinion, and Media's (SOM) annual surveys of random samples of the Swedish population. In total 3,400 residents, in the age span 16 to 85 years, were randomly drawn from the Swedish national registry. The survey was then distributed to these individuals by mail in the fall of 2016. The net response rate was 52\% (Arkhede et al., 2017). The sample did not meaningfully differ from the Swedish population with respect to sex, education, and region. We only include in the following analysis participants who answered the questions about time pressure and emotional wellbeing at work and in free time. For our analysis we therefore retained 850 participants, 63 of whom reported that they were small-business owners, and 787 who reported that they were employed wage earners.

\subsection{Measures}

\subsubsection{Time pressure}

We used separate measures of time pressure at work and in free time. Participants rated their degree of agreement to two statements using a 4-point scale with the response categories "Agree completely", "Agree somewhat", "Do not agree", and "Do not agree at all”. The at-work statement was "I frequently feel that I don't have enough time to complete my job assignments", and the infree-time statement "I frequently feel that I don't have enough time to do what I want in my free time".

\subsubsection{Emotional wellbeing}

We also used separate measures of emotional wellbeing at work and in free time. To measure emotional wellbeing at work, participants were asked "If you think about your job during the past days, how would say that you felt?", and to measure emotional wellbeing in free time "If you think about your free time during the past days, how would say that you felt?" Answers to both questions were recorded on an 11-point numerical scale with the endpoints "In a very bad mood" (0) and (10) "In a very good mood". 


\subsection{Results}

Table 1 shows means, standard deviations, and skewness of the ratings of time pressure and emotional wellbeing. As may be seen, small-business owners experienced significantly higher time pressure at work than the employed wage earners, $\mathrm{t}(104.23)=3.18, \mathrm{p}=.002, \mathrm{~d}=0.34$, and at work emotional wellbeing is also higher for small-business owners than for employed wage earners, $\mathrm{t}(102.85)=3.01, \mathrm{p}=.003, \mathrm{~d}=.38$. In free time there are no significant differences between the two groups. The product moment correlations between time pressure and emotional wellbeing are negative at work $(\mathrm{r}=-.19, \mathrm{p}=.089$, for the small-business owners; $\mathrm{r}=-.17, \mathrm{p}<.001$, for the employed wage earners), and negative but weaker in free time $(r=-.07, p=.508$, for the small-business owners; $r$ $=-.11, \mathrm{p}=.001$, for the employed wage earners).

\subsection{Discussion}

Although the results of Study 1 are only suggestive because of the single-item measures of time pressure and emotional well-being, they confirm that time pressure at work is indeed higher at work for small-business owners than for employed wage earners. This is consistent with the results of previous studies showing that small-business owners work longer hours than employed wage earners (Parasuraman \& Simmers, 2001), and face higher work demands (Nordenmark et al., 2012;

Table 1. Means (M), standard deviations (SD) and skewness (Skew) of ratings of time pressure and emotional well-being at work and in free time made by small-business owners and employed wage earners (Study 1).

\section{Time pressure $\quad$ Emotional wellbeing}

\begin{tabular}{|c|c|c|c|c|c|c|c|c|c|}
\hline \multirow[b]{2}{*}{ Group } & \multirow[b]{2}{*}{$\mathrm{n}$} & \multicolumn{2}{|l|}{ At work } & \multicolumn{2}{|l|}{ In free time } & \multicolumn{2}{|l|}{ At work } & \multicolumn{2}{|l|}{ In free time } \\
\hline & & $\mathrm{M} \quad(\mathrm{SD})$ & Skew & $\mathrm{M} \quad(\mathrm{SD})$ & Skew & $\mathrm{M} \quad(\mathrm{SD})$ & Skew & $\mathrm{M} \quad(\mathrm{SD})$ & Skew \\
\hline $\begin{array}{l}\text { Small-business } \\
\text { owners }\end{array}$ & 63 & $3.13(0.90)$ & -0.67 & $3.01(0.90)$ & -0.64 & $7.60(2.20)$ & -1.25 & $7.44(2.12)$ & -1.01 \\
\hline $\begin{array}{l}\text { Employed wage } \\
\text { earners }\end{array}$ & 787 & $2.80(0.96)$ & -0.28 & $2.99(0.93)$ & -0.57 & $6.85(2.27)$ & -0.81 & $7.47(2.05)$ & -0.97 \\
\hline
\end{tabular}

Prottas \& Thompson, 2006). However, the difference in time pressure was only observed at work and not in free time. Hence, our results do not show spill-over effects from higher time pressure at work to free time, which is unexpected given that previous research has documented that many smallbusiness owners experience high work-family conflict (Johansson Sevä \& Öun, 2015; Prottas \& Thompson 2006).

Another expected finding is that for both small-business owners and employed wage earners, and both at work and in free time, there is a negative relationship between time pressure and emotional wellbeing. We also found that at work, although not in free time, emotional wellbeing is higher for small-business owners than for employed wage earners. This is in line with previous research (Binder \& Coad, 2016) showing that work satisfaction is higher among self-employed workers, whereas satisfaction with free time does not differ. A possible explanation is that other positive factors influence small-business owners' satisfaction and emotional wellbeing at work, such 
as work autonomy (Lange, 2012). This may also explain the paradoxical finding that small-business owners experience both higher time pressure and higher emotional wellbeing than wage earners.

\section{Study 2}

In Study 2 we used survey data from a larger sample of small-business owners in Sweden to estimate regression models (see Figure 1) corresponding to our three hypotheses. Model 1 posits that experience of time pressure is negatively related to domain satisfaction and therefore to emotional

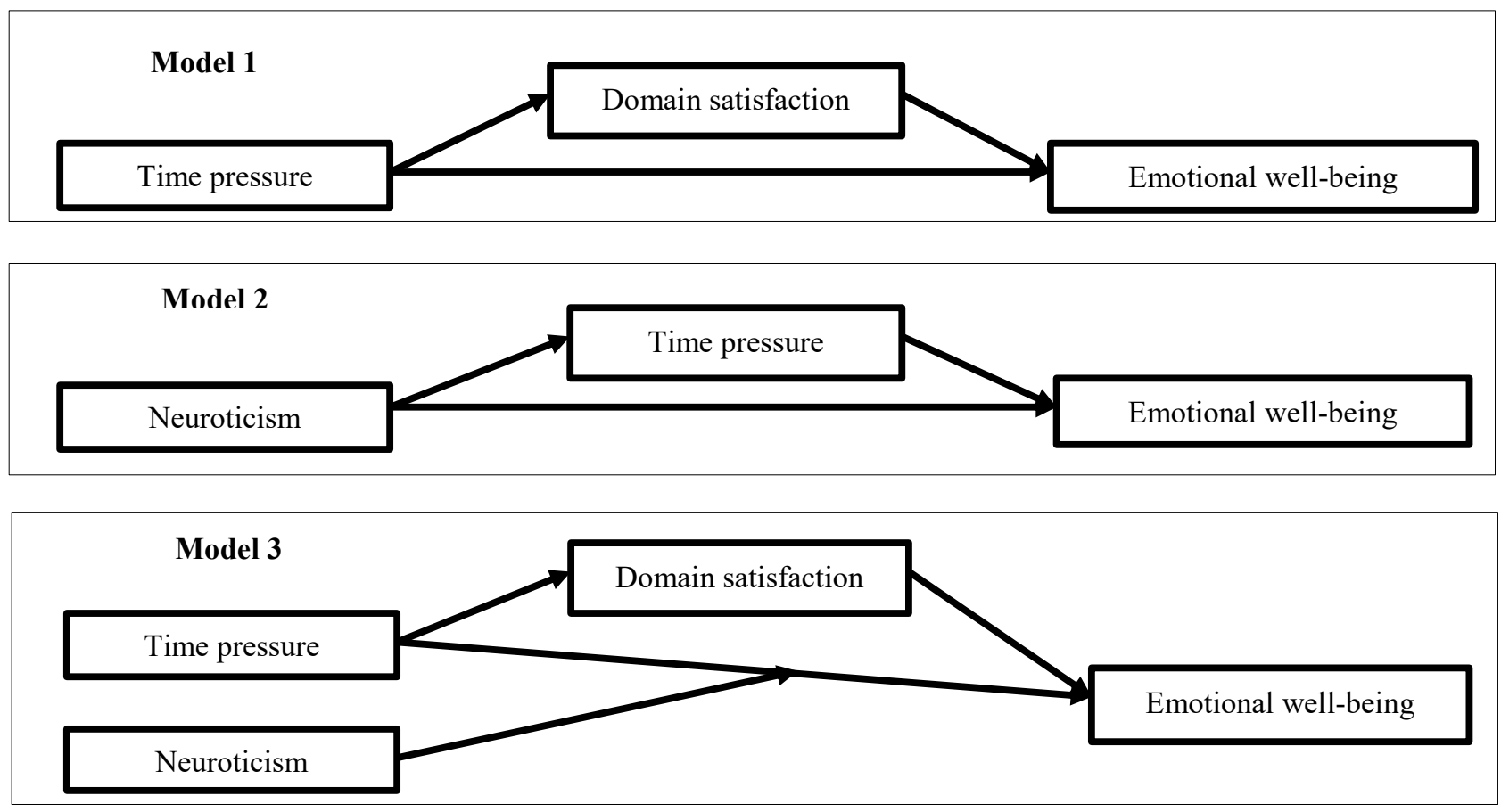

Figure 1. Models of the relationships between neuroticism, emotional well-being, time pressure, and domain satisfaction tested in Study 2.

wellbeing. Model 2 holds that neuroticism is negatively related to time pressure and therefore to emotional wellbeing. Model 3 posits that neuroticism moderates the negative relationship between time pressure and emotional wellbeing.

\subsection{Sample and Procedure}

Participants were recruited from an internet panel consisting of 4,323 small business owners in Sweden. We expected and obtained a sample size equal to the previous study by Gärling et al. (2016), in which the data analyses had an acceptable statistical power. In response to an invitational email, 1,208 participants agreed to participate corresponding to a response rate of $27.9 \%$. They were asked to complete an online survey including 109 questions. We decided in advance which of these questions to be used to construct the measures (described below). In the analyses we retained 1,102 participants who answered all these questions. A majority were men (814 or $73.0 \%)$, aged between 45 and 64 years old (988 or $89.7 \%$ ), and cohabiting with a partner (931 or $85.9 \%$ ). 


\subsection{Measures}

\subsubsection{Neuroticism}

All Big-Five personality traits were measured with the mini-IPIP scale (Donnellan et al. 2006). Participants were asked to rate agreement or disagreement to four statements for each trait (e.g. "Have frequent mood swings"). Response alternatives ranged from 1 ("Disagree strongly") to 5 ("Agree strongly"). An index of neuroticism was constructed by first reverse-coding the positive items (e.g. "Am relaxed most of the time"), and then averaging the four items to an index. Although we only planned to use neuroticism, we correlated the measures of all the Big-Five personality traits with the measure of time pressure (described next). In addition to neuroticism, only conscientiousness had a significant correlation with time pressure at work $(\mathrm{r}=-.17, \mathrm{p}<.001)$ and in free time $(\mathrm{r}=-.13, \mathrm{p}<.001)$.

\subsubsection{Time pressure}

We constructed separate measures of time pressure at work and in free time by adapting the overall self-report measure used in Gärling et al. (2016). The measure of time pressure at work was obtained from agreement ratings on 7-point scales, ranging from 1 ("Disagree strongly") to 7 ("Agree strongly"), in response to the statements: "I frequently feel that I don't have enough time to complete my job assignments"; "At my job, I frequently feel I need to hurry to be in time"; and "I frequently feel rushed due to insufficient time at work". The parallel statements of time pressure in free time were: "I frequently feel that I don't have enough time to do what I want to do in my free time"; "During my free time, I frequently feel I need to hurry to be on time"; and "I frequently feel rushed due to insufficient time during my free time". Indexes were constructed by averaging the ratings of the statements about time pressure at work and the ratings of time pressure in free time. Time pressure at work was strongly correlated with time pressure in free time $(r=.71, p<.001)$, and the reported number of hours worked per week was positively correlated with both time pressure at work $(\mathrm{r}=.44, \mathrm{p}<.001)$ and time pressure in free time $(\mathrm{r}=.36, \mathrm{p}<.001)$.

\subsubsection{Domain satisfaction}

Domain satisfaction at work was measured using three items capturing satisfaction with work as a small business owner. Ratings of satisfaction or dissatisfaction were made of the "business as a whole", "revenue", and "profitability", using a seven-point scale ranging from 0 ("Very dissatisfied") to 6 ("Very satisfied"). An index of domain satisfaction was constructed by averaging these ratings. To obtain an index of domain satisfaction in free time, the average was calculated of participants' ratings of satisfaction or dissatisfaction with "free time", "family or close relationships," and "friends" using the same scale.

\subsubsection{Emotional wellbeing}

A measure of emotional wellbeing was obtained from retrospective ratings of how frequently different emotions had been experienced the last month, at work and in free time respectively. Six unipolar adjective scales were used, with seven steps ranging from 0 (never) to 6 (very often). The adjectives were taken from the Swedish Core Affect Scale (Västfjäll et al., 2002), which is based on Russell's $(1980,2003)$ theory of core affects varying in the two orthogonal dimensions of valence and activation. Each scale was defined by three adjectives. The adjectives were either: high in valence 
(glad, pleased, happy) or low in valence (sad, displeased, depressed) for a neutral activation; high in both valence and activation (engaged, interested, optimistic) or low in both valence and activation (indifferent, bored, pessimistic); and high in valence and low in activation (serene, calm, relaxed) or low in valence and high in activation (tense, anxious, nervous). An index of emotional wellbeing at work was obtained by first averaging the ratings of the positive-valence adjectives and the reversecoded ratings of the negative-valence adjectives, then transforming the averages to a scale from -6 (maximally negative) to 6 (maximally positive) through 0 (neutral). An index of emotional wellbeing in free time was obtained in the same way.

\subsection{Results}

In order to test our three hypotheses, the variables (see descriptives in Table 2) were inputted to OLS linear regression analyses, followed by mediation analyses with PROCESS version 2.16.2 for SPSS (Hayes, 2013) to test the statistical significance of indirect effects. In Table 3 we show that the first requirement of mediation analyses is fulfilled (Zhao et al., 2010), in that the regressions of time pressure on domain satisfaction and emotional wellbeing, and the regressions of neuroticism on time pressure and emotional wellbeing, all have significant coefficients with the expected signs.

\subsubsection{Model 1}

Our first hypothesis was that domain satisfaction mediates the negative relationship between time pressure and emotional wellbeing. Table 4 shows the results of regressions of emotional wellbeing on domain satisfaction, controlling for the direct effect of time pressure on emotional wellbeing. The indirect effect of time pressure through domain satisfaction is significant, as shown by bias-corrected 


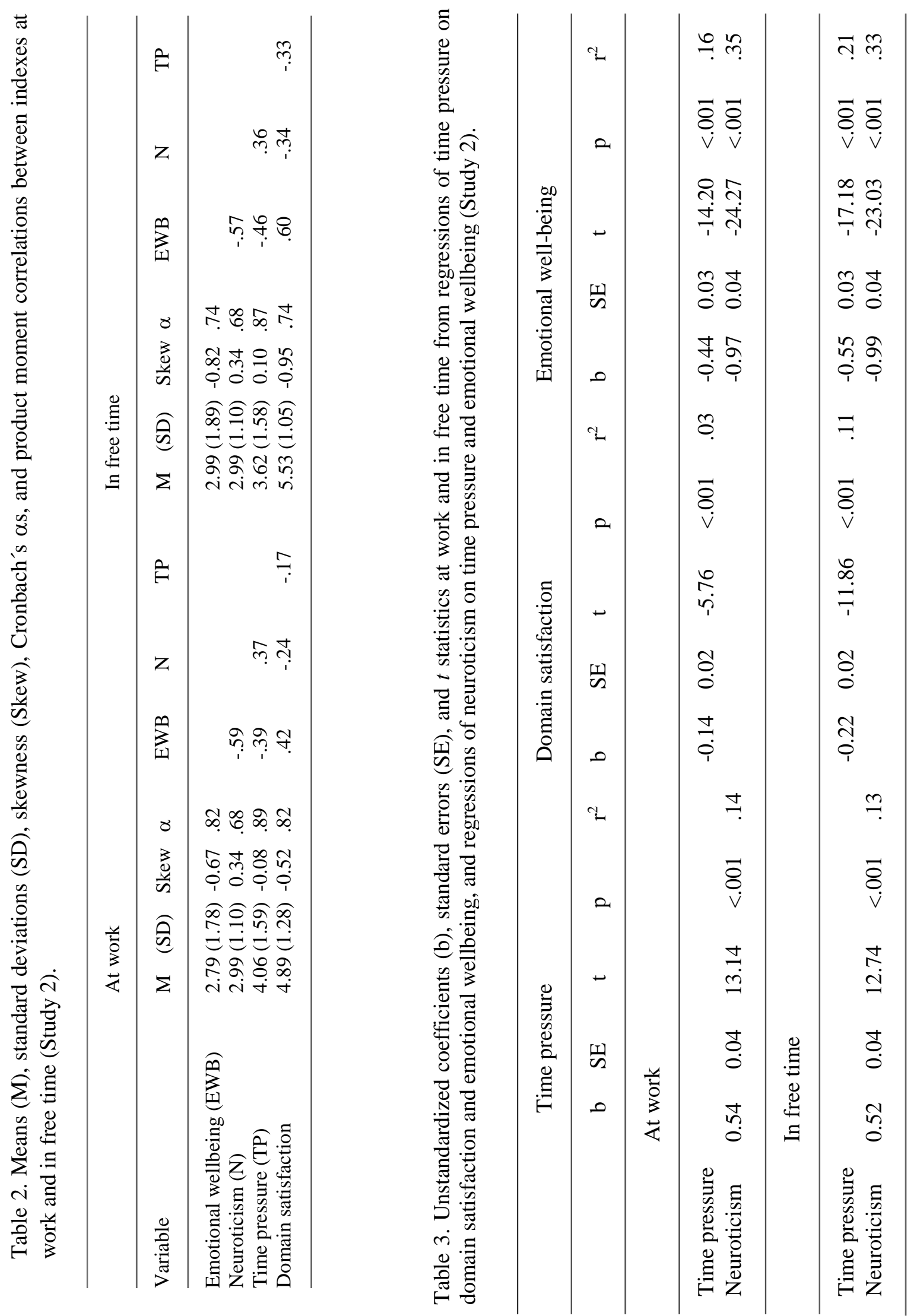


Table 4. Unstandardized regression coefficients (b), standard errors (SE), and $t$ statistics at work and in free time from regressions of emotional well-being on domain satisfaction controlling for time pressure (Study 2).

\begin{tabular}{lccccccccc}
\hline & \multicolumn{7}{c}{ At work } & \multicolumn{7}{c}{ In free time } \\
\hline & $\mathrm{b}$ & $\mathrm{SE}$ & $\mathrm{t}$ & $\mathrm{p}$ & $\mathrm{b}$ & $\mathrm{SE}$ & $\mathrm{t}$ & $\mathrm{p}$ \\
\hline Constant & 1.86 & 0.23 & 7.98 & $<.001$ & -0.74 & 0.30 & -2.99 & .013 \\
Time pressure & -0.37 & 0.03 & -12.79 & $<.001$ & -0.35 & 0.03 & -12.09 & $<.001$ \\
Domain satisfaction & 0.50 & 0.04 & 13.87 & $<.001$ & 0.90 & 0.04 & 20.82 & $<.001$ \\
\hline & \multicolumn{7}{c}{ Adj $\mathrm{R}^{2}=.28 ; \mathrm{F}=214.62$} & & \multicolumn{7}{c}{ Adj $\mathrm{R}^{2}=.44 ; \mathrm{F}=422.43$} \\
\end{tabular}

$95 \%$ confidence intervals $(\mathrm{CI})$ calculated for 2,000 bootstrap replications $(-0.07,95 \% \mathrm{CI}[-0.10,-0.04]$ at work; $-0.20,95 \% \mathrm{CI}[-0.25,-0.16]$ in free time). A partial mediation is indicated since the direct effect of time pressure is significant.

\subsubsection{Model 2}

According to our second hypothesis, time pressure is expected to mediate the relationship between neuroticism and emotional wellbeing. The regression of emotional wellbeing on time pressure reported in Table 5 shows that the coefficient associated with time pressure is significant when controlling for the direct effect of neuroticism on emotional wellbeing. As shown by bias-corrected 95\% confidence intervals calculated for 2,000 bootstrap replications, the indirect effect on emotional wellbeing of neuroticism through time pressure is significant $(-0.12,95 \% \mathrm{CI}[-0.16,-0.09]$ at work; $-0.18,95 \% \mathrm{CI}[-0.23,-0.14]$ in free time). The direct effect of neuroticism on emotional wellbeing remains significant, thus indicating a partial mediation.

Table 5. Unstandardized regression coefficients (b), standard errors (SE), and $t$ statistics at work and in free time from regressions of emotional well-being on time pressure controlling for neuroticism (Study 2).

\begin{tabular}{llllllllll}
\hline & \multicolumn{7}{c}{ At work } & \multicolumn{7}{c}{ In free time } \\
\hline & $\mathrm{b}$ & $\mathrm{SE}$ & $\mathrm{t}$ & $\mathrm{p}$ & $\mathrm{b}$ & $\mathrm{SE}$ & $\mathrm{t}$ & $\mathrm{p}$ \\
\hline Constant & 6.25 & 0.14 & 49.03 & $<.001$ & 6.68 & 0.14 & 46.65 & $<.001$ \\
Neuroticism & -0.84 & 0.04 & -20.25 & $<.001$ & -0.81 & 0.04 & -18.59 & $<.001$ \\
Time pressure & -0.23 & 0.03 & -8.01 & $<.001$ & -0.35 & 0.03 & -11.72 & $<.001$ \\
\hline & Adj R $\mathrm{R}^{2}=.35 ; \mathrm{F}=343.47$ & & \multicolumn{7}{c}{ Adj $\mathrm{R}^{2}=.40 ; \mathrm{F}=366.71$} \\
\end{tabular}




\subsubsection{Model 3}

As shown by bias-corrected $95 \%$ confidence intervals calculated for 2,000 bootstrap replications, the indirect relationship between emotional wellbeing and neuroticism through time pressure is significant, both at work $(-0.05,95 \% \mathrm{CI}[-0.08,-0.03])$ and in free time $(-0.16,95 \% \mathrm{CI}[-0.20,-0.13])$. In Table 6, neuroticism is furthermore shown to significantly moderate the direct effect of time pressure on emotional wellbeing. Time pressure has stronger direct relationships with emotional wellbeing at high levels of neuroticism $(+1 \mathrm{SD}=4.08)$, both at work $(\mathrm{b}=-.26, \mathrm{SE}=.037, \mathrm{p}<.001)$ and in free time $(\mathrm{b}=-.30$, $\mathrm{SE}=.035, \mathrm{p}<.001)$. The relationship is weaker at low levels of neuroticism $(-1 \mathrm{SD}=1.90)$, both at work $(\mathrm{b}=-.15, \mathrm{SE}=.035, \mathrm{p}<.001)$ and in free time $(\mathrm{b}=-.16, \mathrm{SE}=.036, \mathrm{p}<.001)$. The moderation by neuroticism of the relationship between time pressure and emotional well-being is displayed graphically in Figure 2 , with the $\mathrm{X}$-axis representing percentile ranks of neuroticism, and the Y-axis the effect of time pressure on emotional wellbeing. As can been seen, the strength of the negative relationship between time pressure and emotional wellbeing increases with neuroticism.

\subsection{Discussion}

Our main findings for both work and free time are consistent with the proposed hypotheses. Firstly, time pressure is negatively related to emotional wellbeing, both directly and also indirectly through domain satisfaction. Secondly, neuroticism is negatively related to emotional wellbeing in three ways: directly; indirectly through time pressure; and by moderating the direct negative relationship between time pressure and emotional wellbeing.

We interpret the mediation by domain satisfaction of the negative relationship between time pressure and emotional wellbeing to be consistent with the results of Gärling et al. (2016) and the conceptual model proposed by Gärling et al. (2014). In Gärling et al. (2016), a direct measure of goal progress was used. This posited that satisfaction should increase with the outcomes of progress

Table 6. Unstandardized regression coefficients (b), standard errors (SE), and $t$ statistics at work and in free time from regressions of emotional well-being on the interaction between neuroticism and time pressure controlling for neuroticism, time pressure, and domain satisfaction (Study 2).

\begin{tabular}{|c|c|c|c|c|c|c|c|c|}
\hline & \multicolumn{4}{|c|}{ At work } & \multicolumn{4}{|c|}{ In free time } \\
\hline & $\mathrm{b}$ & SE & $\mathrm{t}$ & $\mathrm{p}$ & $\mathrm{b}$ & SE & $\mathrm{t}$ & $\mathrm{p}$ \\
\hline Constant & 3.35 & 0.35 & 9.57 & $<.001$ & 0.91 & 0.38 & 2.39 & .017 \\
\hline Neuroticism & -.053 & 0.10 & -5.07 & $<.001$ & -0.37 & 0.09 & -4.15 & $<.001$ \\
\hline Time pressure & -0.05 & 0.07 & -0.65 & .513 & -0.03 & 0.07 & -.44 & .661 \\
\hline Domain satisfaction & 0.39 & 0.03 & 12.03 & $<.001$ & 0.74 & 0.04 & 18.29 & $<.001$ \\
\hline Neuroticism $\mathrm{x}$ & -0.05 & 0.02 & -2.36 & .018 & -0.07 & 0.02 & -3.07 & .002 \\
\hline \multicolumn{9}{|l|}{ Time pressure } \\
\hline & \multicolumn{4}{|c|}{ Adj $R^{2}=.46 ; F=233.12$} & \multicolumn{4}{|c|}{$\operatorname{Adj} R^{2}=.54 ; F=327.56$} \\
\hline
\end{tabular}




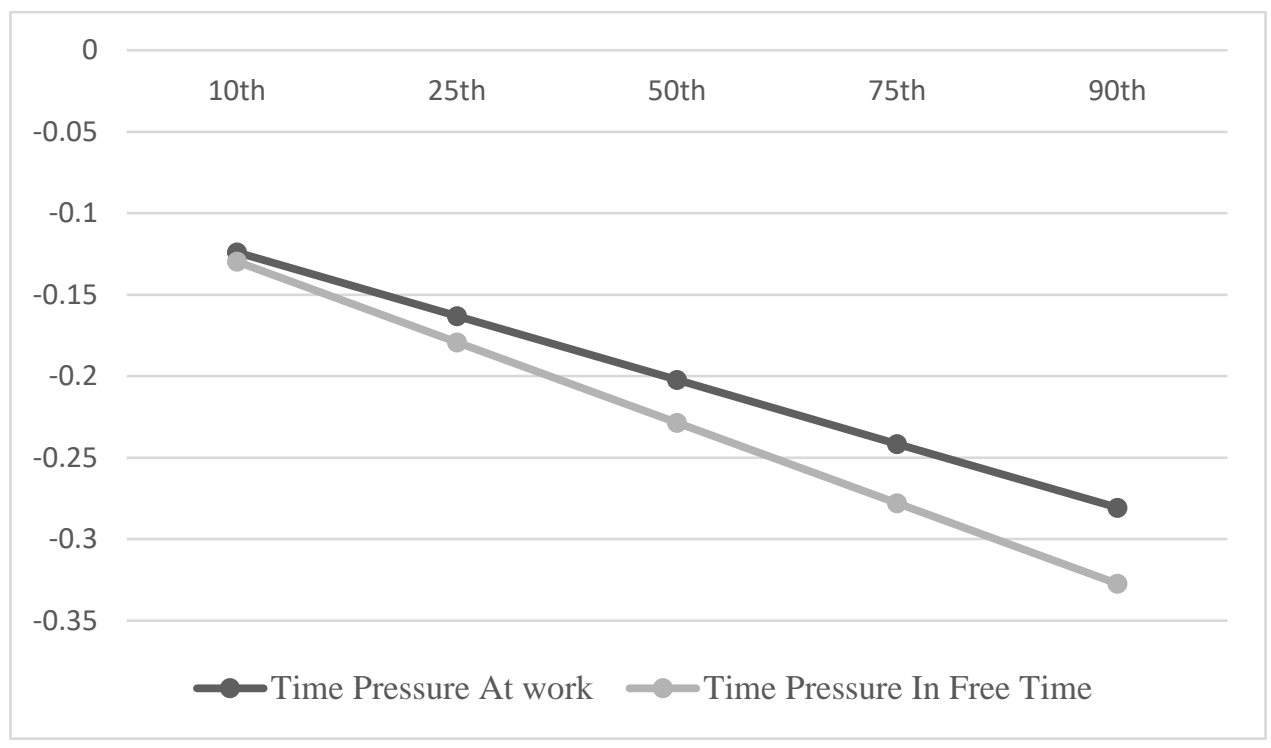

Figure 2. Moderation by neuroticism of the relationship between time pressure and emotional wellbeing in Study 2. (The X-axis represents percentile ranks of neuroticism and the Y-axis the effect of time pressure on emotional well-being.)

toward different goals (e.g., business revenue, close social relations), and therefore domain satisfaction would become an aggregated indirect measure of goal progress (Lent et al. 2005). The results may hence be considered to be a conceptual replication of the results of Gärling et al. (2016) that strengthens the theoretical position of Gärling et al. (2014).

The mediation by domain satisfaction here was partial, as goal progress was in Gärling et al. (2016). In the previous study, a parallel mediator was self-reported stress symptoms. This suggested that, at least for some people or for most people in many situations, time pressure has stress effects. In line with this, we found that neuroticism strengthened the negative relationship between time pressure and emotional wellbeing, both at work and in free time. Our aim was not to investigate explanations for this interaction. Still, we note that a possible explanation is that individuals high in neuroticism use maladaptive strategies to cope with time pressure, for instance, by using emotionfocused coping strategies instead of problem-focused strategies (Hutchinson \& Williams, 2007). Future research should investigate potential explanations of the interaction between neuroticism and time pressure on emotional wellbeing.

Confirming previous research (e.g. Steel et al. 2008), we found a negative relationship between neuroticism and emotional wellbeing. This relationship was only partially explained by time pressure, suggesting other potential mediators, such as loneliness, poor sleep quality, and low social status, all of which have been shown to decrease emotional wellbeing (Anderson et al., 2012; Kahneman \& Krueger, 2006; Steptoe 2008) and have a higher prevalence in high-neuroticism than low-neuroticism individuals (Anderson et al., 2001; Hintsanen et al., 2014; Saklofske \& Yackulic, 1989). Neuroticism may also reduce emotional wellbeing independently of situational factors, since individuals high in neuroticism appear to have a higher set-point for negative emotions than individuals low in neuroticism (Ormel et al., 2012).

\section{General Discussion}


Study 1 showed that, in a representative sample of the adult Swedish population, there is a negative relationship between time pressure and emotional wellbeing, both at work and in free time. The study also showed that time pressure at work was higher among small-business owners than employed wage earners. The negative relationship between time pressure and emotional wellbeing was replicated in Study 2 for a larger sample of small business owners. These findings are consistent with the results of two previous studies of Swedish wage earners (Gärling et al., 2016). Although the use of single-item measures of time pressure and emotional wellbeing in Study 1 is a limitation, Study 2 used reliable multi-item measures, yielding similar results. Whether the results generalize to other populations and contexts should be addressed in future research. The relationship between time pressure and emotional well-being may differ depending on culturally-influenced value orientations, such as whether these orientations emphasize materialistic or non-materialistic values (see Delhey, 2010). Since the Swedish culture emphasizes relatively non-materialistic values, and therefore the importance of leisure time over work, the relationships may differ for people in other countries with other value orientations. In more materialistic cultures, for instance, people in general are more likely to prioritize work over leisure time, which likely increases the negative effect of time pressure on emotional wellbeing, since such values imply that work goals should be relatively more important than goals pursued in free time.

In order to implement policies that aim at reducing the negative effects of time pressure on emotional wellbeing, it is important to understand which factors mediate and moderate their relationship. Study 2 demonstrated the mediating role of domain satisfaction, and the mediatingmoderating roles of the Big-5 personality trait neuroticism. Both findings clarify and extend the results of Gärling et al. (2016), namely that goal progress and self-reported stress symptoms are parallel mediators of the negative relationship between time pressure and emotional well-being. Mediational analyses of the type of cross-sectional data we analyzed have however been criticized (e.g., Maxwell \& Cole, 2007; Maxwell et al., 2011) for providing biased estimates of mediation parameters based on time-lagged measurements. According to our hypotheses, at an individual level, changes in time pressure precede and cause changes in domain satisfaction (interpreted as an indicator of progress toward different goals), which in turn precede and cause changes in emotional wellbeing. These influences are assumed to be short-term but to occur repeatedly. In individuals high in neuroticism, the influences may be more frequent than in individuals low in neuroticism. In the survey, we measured time pressure, domain satisfaction, and emotional wellbeing by means of retrospective self-reports. If our measures then reflect invariant correlations repeated across time, our data should not be open to the suggested criticism.

In the absence of longitudinal or experimental data, there are still limitations in terms of inferring the causal directions implied by the models we have tested. Thoemmes (2015) argued that causal inferences are justified if verified by other experimental or longitudinal research. We therefore note that studies have demonstrated positive effects on emotional wellbeing of training in time management (MacLeod et al., 2008), and that in the meta-analysis of Klug and Maier (2013), experimental studies are included that permit inferences that the relationship between goal progress and emotional wellbeing is causal. Furthermore, in a review of time-lagged observations, Schimmack (2008) concludes that the reverse direction of the influence of emotional wellbeing on domain satisfaction is weak or absent. Neuroticism is generally found to be substantially inherited and therefore stable (McCrae et al. 2011), thus negating a reverse causal direction of the relationship between neuroticism and the strength of the response to changes in time pressure. 
Our proposed mediational-moderator models are not compared to alternative models. Doing this is a practice not recommended (Kline, 2015; Thoemmes, 2015). The models are tests of the hypotheses we proposed, and we conclude that the hypotheses are not refuted by the results. This does not preclude additional research aimed at developing theory and refining the hypotheses. One avenue for such research is to distinguish positive from negative emotions. The value of doing this is supported by a recent meta-analysis showing that accumulated neuropsychological evidence favors the theoretical position that positive and negative emotions are not end-points of a bipolar continuum (Lindquist et al., 2015). It is recognized that time pressure has both positive and negative effects (Garhammer, 2002). A question that may be asked is therefore whether positive effects of time pressure - such as mobilization of mental resources, sharpened attention, and improved achievement - are accompanied by positive emotions. Although it was not our aim to answer this question, it seems worthwhile to try to do so in future research.

We have demonstrated that both time pressure and emotional wellbeing are higher for smallbusiness owners than employed wage earners, whereas the relationship with emotional wellbeing remains negative. However, our results also showed that this relationship does not pertain equally to all small-business owners, since neuroticism strengthens the negative relationship between time pressure and emotional well-being. A possible interpretation is that high-neuroticism individuals are more susceptible to time stress than low-neuroticism individuals. Another worthwhile purpose would be to investigate in future research how and why time pressure results in time stress.

The fact that small-business owners experience both high levels of time pressure and high emotional well-being suggests that owning a small business has both positive and negative consequences (Prottas \& Thompson, 2006). If policy makers want to stimulate small-business ownership, they need to recognize the negative relationship between small-business owners' time pressure and emotional experiences. One possibility would be to offer training programs, providing small-businesses owners with adequate strategies for coping with the stressful conditions associated with owning a small business (e.g. MacLeod et al., 2008). Another possibility is to make changes to decrease the work load, for instance, by providing administrative support. If nothing is done, the disadvantages associated with owning a business may hinder the development of small-businesses in society, which in turn would have negative consequences for economic growth and job creation.

We finish by arguing that the negative relationship between time pressure and wellbeing is likely to exist in many other occupational groups in Western societies (Haller et al., 2013). This also needs to be investigated and documented. Whether the relationship is always mediated-moderated by the factors identified in the current studies is an open question.

\section{Acknowledgements}

The data collection was funded by The Swedish Federation of Business Owners. We thank René Bongard who conducted the data collection and André Hansla for advice about the mediational-moderation analyses. We thank three reviewers for valuable comments.

\section{Compliance with ethical standards}

We have followed ethical standards in conducting the survey including request of informed consent, permitting voluntarily withdrawal at any point of the survey, and anonymizing data records. None of the authors have any conflict of interest. 


\section{Authors}

Filip Fors Connolly

Umeå University

Ingemar Johansson Sevä

Umeå University

Tommy Gärling

University of Gothenburg

Tommy.Garling@psy.gu.se

\section{Publishing Timeline}

Received 27 November 2018

Accepted 4 February 2020

Published 1 June 2020

\section{References}

Anderson, C., John, O. P., Keltner, D., \& Kring, A. M. (2001). Who attains social status? Effects of personality and physical attractiveness in social groups. Journal of Personality and Social Psychology, 81, 116-132. doi: 10.1037/0022-3514.81.1.116

Anderson, C., Kraus, M. W., Galinsky, A. D., \& Keltner, D. (2012). The local-ladder effect: Social status and subjective well-being. Psychological Science, 23, 764-771. doi: 10.1177/0956797611434537

Arkhede, S., Bové, J., Bové, K., \& Jansson, D. (2017). SOM-undersökningarna 2016-en metodöversikt (The SOM surveys 2016 - overview of method). Göteborg, Sweden: University of Gothenburg, The SOM Institute. www.som.gu.se/som_institute

Binder, M., \& Coad, A. (2016). How satisfied are the self-employed? A life domain view. Journal of Happiness Studies, 17(4), 1409-1433. doi: 10.1007_s10902-015-9650-8

Busseri, M. A., \& Sadava, S. W. (2011). A review of the tripartite structure of subjective well-being: Implications for conceptualization, operationalization, analysis, and synthesis. Personality and Social Psychology Review, 15, 290-314. doi: 10.1177/1088868310391271

Byrne, K. A., Silasi-Mansat, C. D., \& Worthy, D. A. (2015). Who chokes under pressure? The Big-Five personality traits and decision making under pressure. Personality and individual Differences, 74, 22-28. doi: 10.1016/j.paid.2014.10.009

Costa, P. T., \& McCrae, R. R. (1985). Hypochondriasis, neuroticism, and aging: When are somatic complaints unfounded? American Psychologist, 40(1), 19-28. doi: 10.1037/0003-066X.40.1.19

Delhey, J. (2010). From materialist to post-materialist happiness? National affluence and determinants of life satisfaction in cross-national perspective. Social Indicators Research, 97(1), 65-84. doi: 10.1007/s11205-0099558-y.

Diener, E., \& Chan, M. Y. (2011). Happy people live longer: Subjective well-being contributes to health and longevity. Applied Psychology: Health and Well-Being, 3, 1-43. doi:10.1111/j.1758-0854.2010.01045.x.

Diener, E., \& Suh, E. (1997) Measuring quality of life: economic, social, and subjective indicators. Social Indicators Research, 40, 189-216. doi: 10.1023/A:1006859511756

Diener, E., Larsen, R. J., Levine, S., \& Emmons, R. A. (1985). Intensity and frequency dimensions underlying positive and negative affect. Journal of Personality and Social Psychology, 48, 1253-1265. doi: 10.1037/0022-3514.48.5.1253

Donnellan, M. B., Oswald, F. L., Baird, B. M., \& Lucas, R. E. (2006). The mini-IPIP scales: tiny-yet-effective 
measures of the Big Five factors of personality. Psychological Assessment, 18, 192-203. doi: 10.1037/10403590.18.2.192

Garhammer, M. (2002). Pace of life and enjoyment of life. Journal of Happiness Studies, 3, 217-256. doi: 10.1023/A:1020676100938

Goodin, R. E., Rice, J. M., Bittman, M., \& Saunders, P. (2005). The time-pressure illusion: Discretionary time vs. free time. Social Indicators Research, 73, 43-70. doi: 10.1007/s11205-004-4642-9

Gärling, T., Gamble, A., Fors, F., \& Hjerm, M. (2016). Emotional well-being related to time pressure, impediment to goal progress, and stress-related symptoms. Journal of Happiness Studies, 17, 1789-1799. doi: 10.1007/s10902-015-9670-4

Gärling, T., Krause, K., Gamble, A., \& Hartig, T. (2014). Time pressure and emotional well-being. PsyCH Journal, 3, 132-143. doi: 10.1002/pchj.52

Haller, M., Hadler, M., \& Kaup, G. (2013). Leisure time in modern societies: A new source of boredom and stress? Social Indicators Research, 111, 403-434. doi: 10.1007/s11205-012-0023-y

Hartig, T., Johansson, G., \& Kylin, C. (2003). Residence in the social ecology of stress and restoration. Journal of Social Issues, 59, 611-636. doi: 10.1111/1540-4560.00080

Hayes, A. E. (2013). Introduction to mediation, moderation, and conditional process analysis: A regressionbased approach. London: Guilford Press.

Hill Rice, V. (Ed.) (2012). Handbook of stress, coping, and health. Thousand Oakes, CA: Sage.

Hintsanen, M., Puttonen, S., Smith, K., Törnroos, M., Jokela, M., Pulkki-Råback, L., ... \& Venn, A. (2014). Fivefactor personality traits and sleep: Evidence from two population-based cohort studies. Health Psychology, 33, 1214-1223. doi; 10.1037/hea0000105

Hutchinson, J. G., \& Williams, P. G. (2007). Neuroticism, daily hassles, and depressive symptoms: An examination of moderating and mediating effects. Personality and Individual Differences, 42, 1367-1378. doi: 10.1016/j.paid.2006.10.014

Johansson Sevä, I., \& Öun, I. (2015). Self-employment as a strategy for dealing with the competing demands of work and family? The importance of family/lifestyle motives. Gender, Work \& Organization, 22(3), 256272. doi: 10.1111/gwao.12076.

Kahneman, D. (1999). Objective Happiness. In D. Kahneman, E. Diener \& N. Schwarz (Eds.), Well-being: The foundations of hedonic psychology (pp. 3-25). New York: Russel Sage Foundation.

Kahneman, D., \& Krueger, A. B. (2006). Developments in the measurement of subjective well-being. Journal of Economic perspectives, 20(1), 3-24. doi: 10.1257/089533006776526030

Kline, R. B. (2015). The mediation myth. Basic and Applied Social Psychology, 37(4), 202-213. doi: 10.1080/01973533.2015.1049349

Klug, H. J. P., \& Maier, G. W. (2014). Linking goal progress and subjective well-being: A meta-analysis. Journal of Happiness Studies, 16, 37-65. doi: 10.1007/s10902-013-9493-0.

Lange, T. (2012). Job satisfaction and self-employment: autonomy or personality?. Small business economics, 38(2), 165-177. doi: 10.1007/s11187-009-9249-8

Leiter, M. P., \& Durup, M. J. (1996). Work, home, and in-between: A longitudinal study of spillover. Journal of Applied Behavioral Science, 32, 29-47. doi: 10.1177/0021886396321002.

Lent, R. W., Singley, D., Sheu, H. B., Gainor, K. A., Brenner, B. R., Treistman, D., \& Ades, L. (2005). Social cognitive predictors of domain and life satisfaction: Exploring the theoretical precursors of subjective well-being. Journal of Counseling Psychology, 52, 429-442. doi: 10.1037/0022-0167.52.3.429

Lindquist, K. A., Satpute, A. B., Wager, T. D., Weber, J., \& Barrett, L. F. (2015). The brain basis of positive and negative affect: Evidence from a meta-analysis of the human neuroimaging literature. Cerebral Cortex, 26(5), 1910-1922. doi: 10.1093/cercor/bhv001

Lommen, M. J., Engelhard, I. M., \& van den Hout, M. A. (2010). Neuroticism and avoidance of ambiguous stimuli: Better safe than sorry? Personality and Individual Differences, 49, 1001-1006. doi:

10.1016/j.paid.2010.08.012 
Manolis, C., \& Roberts, J. A. (2012). Subjective well-being among adolescent consumers: The effects of materialism, compulsive buying, and time affluence. Applied Research in Quality of Life, 7, 117-135. doi: 10.1007/s11482-011-9155-5

MacLeod, A. K., Coates, E., \& Hetherton, J. (2008). Increasing well-being through teaching goal-setting and planning skills: Results of a brief intervention. Journal of Happiness Studies, 9, 185-196. doi: 10.1007/s10902-007-9057-2

Mani, A., Mullainathan, S., Shafir, E., \& Zhao, J. (2013). Poverty impedes cognitive function. Science, 341(6149), 976-980. doi: 10.1126/science.1238041

Maxwell, S. E., \& Cole, D. A. (2007). Bias in cross-sectional analyses of longitudinal mediation. Psychological Methods, 12, 23-44. doi: 10.1037/1082-989X.12.1.23

Maxwell, S. E., Cole, D. A., \& Mitchell, M. A. (2011). Bias in cross-sectional analyses of longitudinal mediation: Partial and complete mediation under an autoregressive model. Multivariate Behavioral Research, 46, 816-841. doi: 10.1080/00273171.2011.606716

McCrae, R. R., Kurtz, J. E., Yamagata, S., \& Terracciano, A. (2011). Internal consistency, retest reliability, and their implications for personality scale validity. Personality and Social Psychology Review, 15, 28-50. doi; $10.1177 / 1088868310366253$

Ng, W., Diener, E., Arora, R., \& Harter, J. (2009). Affluence, feelings of stress, and well-being. Social Indicators Research, 94, 257-271. doi: 10.1007/s11205-008-9422-5

Nordenmark, M., Vinberg, S., \& Strandh, M. (2012). Job control and demands, work-life balance and wellbeing among self-employed men and women in Europe. Vulnerable Groups \& Inclusion, 3(1), 18896.

Novaco, R. W., \& Gonzales, O. I. (2009). Commuting and well-being. In Y. Amichai-Hamburger (Ed.), Technology and well-being (pp. 174-205). New York: Cambridge University Press.

Ormel, J., Riese, H., \& Rosmalen, J. G. (2012). Interpreting neuroticism scores across the adult life course: immutable or experience-dependent set points of negative affect? Clinical Psychology Review, 32, 71-79. doi: 10.1016/j.cpr.2011.10.004

Parasuraman, S., \& Simmers, C. A. (2001). Type of employment, work-family conflict and well-being: a comparative study. Journal of Organizational Behavior: The International Journal of Industrial, Occupational and Organizational Psychology and Behavior, 22(5), 551-568. doi: 10.1002/job.102

Proctor, R. W., \& van Zandt, T. (2018). Human factors in simple and complex systems (3rd ed.). Boca Raton, FL: CRC Press.

Prottas, D. J., \& Thompson, C. A. (2006). Stress, satisfaction, and the work-family interface: A comparison of self-employed business owners, independents, and organizational employees. Journal of Occupational Health Psychology, 11(4), 366-378. doi: 10.1037/1076-8998.11.4.366

Russell, J. A. (1980). A circumplex model of core affect. Journal of Research in Personality, 11, 273-294. doi: 10.1016/0092-6566(77)90037-X;

Russell, J. A. (2003). Core affect and the psychological construction of emotion. Psychological Review, 110, 145-172. doi: 10.1037/0033-295X.110.1.145

Saklofske, D. H., \& Yackulic, R. A. (1989). Personality predictors of loneliness. Personality and Individual Differences, 10, 467-472. doi: 10.1016/0191-8869(89)90011-1

Schimmack, U. (2008). The structure of subjective well-being. In M. Eid \& R. J. Larsen (Eds.) The science of subjective well-being (pp. 97-123). New York: Guilford Press.

Sonnentag, S. (2012). Psychological detachment from work during leisure time: The benefits of mentally disengaging from work. Current Directions in Psychological Science, 21(2), 114-118. doi: $10.1177 / 0963721411434979$

Steel, P., Schmidt, J., \& Shultz, J. (2008). Refining the relationship between personality and subjective wellbeing. Psychological Bulletin, 134, 138-161. doi: 10.1037/0033-2909.134.1.138

Steptoe, A., O'Donnell, K., Marmot, M., \& Wardle, J. (2008). Positive affect, psychological well-being, and good sleep. Journal of Psychosomatic Research, 64, 409-415. doi: 10.1016/j.jpsychores.2007.11.008 
Strazdins, L., Griffin, A. L., Broom, D. H., Banwell, C., Korda, R., Dixon, J., Paolucci, F., \& Glover, J. (2011). Time scarcity: Another health inequality? Environment and Planning A, 43, 545-559. doi: 10.1068/a4360

Suls, J. (2001). Affect, stress, and personality. In J. P. Forgas (Ed.), Handbook of affect and social cognition (pp. 392-409). Mahwah, NJ: Erlbaum.

Thoemmes, F. (2015). Reversing arrows in mediation models does not distinguish plausible models. Basic and Applied Social Psychology, 37(4), 226-234. doi: 10.1080/01973533.2015.1049351

Tov, W. (2018). Well-being concepts and components. In E. Diener, S. Oishi \& L. Tay (Eds.), Handbook of well-being. Salt Lake City, UT: DEF Publishers. doi: nobascholar.com

Trougakos, J. P., Beal, D. J., Green, S. G., \& Weiss, H. M. (2008). Making the break count: An episodic examination of recovery activities, emotional experiences, and affective delivery. Academy of Management Journal, 51,131-146. doi: 10.1007/s10902-007-9066-1

Västfjäll, D., Friman, M., Gärling, T., \& Kleiner, M. (2002). The measurement of core affect: A Swedish selfreport measure derived from the affect circumplex. Scandinavian Journal of Psychology, 43, 19-31. doi: 10.1111/1467-9450.00265

Zhao, X., Lynch, J. G. Jr., \& Chen, Q. (2010). Reconsidering Baron and Kenny: Myths and truths about mediation analysis. Journal of Consumer Research, 37, 197-206. doi: 10.1086/651257 